is not necessarily marked out for relentless progression to other parts of the colon, whether resection is undertaken or not. Most patients who have localized disease when first seen do not develop disease proximally and even in severely involved persons a second resection is seldom necessary.

Over half of the patient had symptoms for less than one month when first seen at hospital, and yet many had pronounced and serious complications. The fact that over half of the fatalities occurred in this group is worrying, since little can be done to prevent the catastrophic presentation of these patients until the aetiology is better understood.

In this study the immediate risk to life during the first hospital admission was $3 \%$. This figure was considerably higher in patients with complications. Most patients died because of inflammatory complications. In addition to the patients in this series with a firm diagnosis of diverticular disease, a further small number of elderly patients with suspected diverticular disease were admitted to hospital during the period under review and died soon after admission with peritonitis, and because they did not have a barium enema or necropsy performed they could not be included in this series. Hence the true mortality during the first hospital admission may be more than $3 \%$.

The complication rate and the necessity for surgical intervention were less frequent in patients with total colon involvement, which seems to incriminate pathology in the distal colon as being most likely to result in the development of a situation demanding surgery. This may encourage the surgeon who finds it necessary or expedient to leave behind a segment of proximal colon with several diverticula when resecting the distal colon in diverticular disease. If this line of management has to be adopted it is rare for a second operation to be required to deal with complications in the proximal segment.

It has been suggested that diverticular disease may be a sequel to the irritable colon syndrome (Almy, 1965; Manousos et al., $1967 \mathrm{~b}$ ) on the basis of similarities of some but not all features of intestinal motility (Arfwidsson, 1964 ; Manousos et al., $1967 \mathrm{~b}$; Parks et al., 1969). In this series, however, more than one-half of the patients had a history of less than one month, and three-quarters of them had a history of less than one year, on presentation at hospital with established disease. As these patients did not have a prolonged history of symptomatic irritable colon it is unlikely that in them it preceded diverticular disease. It is possible that in some of the remaining patients gut symptoms preceding the development of diverticular disease could have been those of irritable colon, but even this remains speculative.

It is a pleasure to thank Professor H. W. Rodgers, department of surgery, and Professor E. A. Cheeseman, department of statistics, Queen's University, Belfast, for providing facilities to undertake this investigation. I am indebted to Dr. A. M. Connell for his constant advice, help, and encouragement throughout the study. I wish to thank the consultant staff of the Royal Victoria Hospital for permission to study patients under their care ; Mrs. R. Blackman, who carried out much of the secretarial work connected with the clinical survey; and Mrs. J. McCabe, who was responsible for the task of transferring data to punch cards.

\section{REFERENCES}

Almy, T. P. (1965). Gastroenterology, 49, 109.

Arfwidsson, S. (1964). Acta Chirurgica Scandinavica, Suppl. No. 342.

Boles, R. S., jun., and Jordan, S. M. (1958). Gastroenterology, 35, 579. Boles, R. S., jun., and Jordan, S. M. (1958). Gastroenterology, 35, Sritish fournal of Surgery, $47,493$.

Debray, C., Hardouin, J. P., Besançon, F., and Raimbault, J. (1961). Semaine des Hốpitaux de Paris, 37,1743 .

Greene, W. W. (1957). American fournal of Surgery, 94, 282.

Henderson, N. P. (1944). British fournal of Radiology, 17, 197.

Kocour, E. I. (1937). American fournal of Surgery, 37, 433.

McGowan, F. J., and Wolff, W. I. (1952). Gastroenterology, 21, 119.

Manousos, O. N., Truelove, S. C., and Lumsden, K. (1967a). British Medical fournal, 3, 762.

Manousos, O. N., Truelove, S. C., and Lumsden, K. (1967b). British Medical fournal, 3, 760 .

Morson, B. C. (1963). British fournal of Radiology, 36, 385.

Parks, T. G. (1968). Proceedings of the Royal Society of Medicine, 61,

Parks, T. G., Connell, A. M., and Misiewicz, J. J. (1969). Similarities of colonic motor response to prostigmine in diverticular disease and the irritable colon syndrome. In press.

Rankin, F. W., and Brown, P. W. (1930). Surgery, Gyn:cology and Obstetrics, 50, 836.

Spriggs, E. I., and Marxer, O. A. (1927). Lancet, 1, 1067

Telling, W. H. M., and Gruner, O. C. (1917). British fournal of Surgery, 4, 468.

Welch, C. E. (1958). American fournal of Gastroenterology, 29, 374

Welch, C. E., Allen, A. W., and Donaldson, G. A. (1953). Annals of Surgery, 138, 332 .

Williams, I. (1963). British fournal of Radiology, 36, 393.

Williams, I. (1965). British fournal of Radiology, 38, 437.

\title{
Reappraisal of Clinical Features of Diverticular Disease of the Colon
}

\author{
T. G. PARKS,* M.CH., F.R.c.s.
}

\begin{abstract}
Cummary : In patients with diverticular disease of the colon factors which indicate a worse prognosis include widespread abdominal pain, nausea and vomiting, disturbed bowel habit, a palpable abdominal mass, abdominal distension, and any of the inflammatory complications. While radiology is of prime importance in the initial diagnosis, it is often impossible to differentiate between diverticulosis and diverticulitis. A more accurate distinction can be made by assessing all the available clinical, radiological, and pathological data, but again there are limitations and inaccuracies. The use of the term " diverticular disease" is preferable.
\end{abstract}

\section{Introduction}

A previous communication (Parks, 1969) outlines the natural history of patients with diverticular disease of the colon treated at the Royal Victoria Hospital, Belfast, between 1951 and 1965 inclusive, and details of the plan of the investigation have been described. This paper presents the clinical features of the same group of 521 patients.

Clinical and radiological differentiation between diverticulosis and diverticulitis is often difficult and sometimes impossible, but in order to assess if any useful division could be made and to determine if these terms had any prognostic or therapeutic significance this detailed study of the symptomatology has been made.

\section{Material and Methods}

In addition to reviewing the clinical features in the group as a whole, account was taken of patterns in patients with

* Senior Registrar and Senior Tutor, Department of Surgery, Queen's University, Belfast. At present Senior Registrar, Royal Victoria Hospital, Belfast BT12 6BA. 
radiological diagnosis of diverticulosis or diverticulitis and also of the patterns in patients finally categorized as diverticulosis or diverticulitis on the basis of all the available data. A final diagnosis of diverticulitis was made in those patients who had one or more of the following: (a) clinical findings of inflammation-for example, tenderness, pyrexia, mass, leucocytosis ; (b) radiological changes consistent with inflammatory involvement; and (c) histological confirmation of inflammatory change on operative or necropsy specimen.

Of 461 cases who had barium enema performed on first referral to hospital the radiologist considered that 230 had diverticulosis only and 231 had changes consistent with diverticulitis. Of the 521 patients in this series 426 were considered on the clinical, radiological, and pathological grounds to have evidence of classical " diverticulitis." In the remaining 95 cases there was no conclusive evidence of inflammation.

\section{Results}

Site of Pain.-The commonest site of pain was in the lower abdomen, involving both the left and right lower quadrants (Table I), but in most cases the pain was more acute on the left side. The prognosis was better in patients when the pain was localized to the left lower quadrant. During their first hospital admission $15 \%$ of patients with pain in the left lower quadrant required surgery compared with $40 \%$ of those in whom the pain was more widespread. There was no correlation between the site of pain and the site or number of diverticula revealed radiologically.

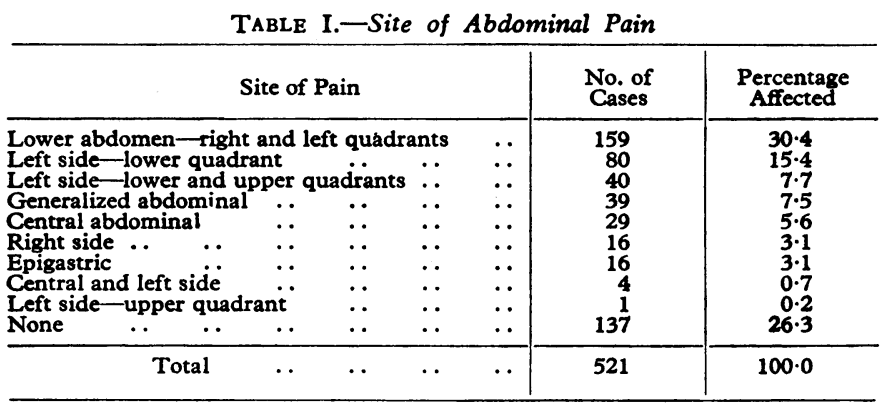

There were 137 patients who had no pain before attendance at hospital and yet 59 of these showed radiological changes consistent with a diagnosis of diverticulitis. The prognosis was better in those patients in whom pain was not a symptom. Only $25(18 \%)$ of 137 patients in this category came to surgery during the follow-up period compared with 133 (35\%) of the 384 patients in whom pain was a symptom.

Nature of Pain.-The nature of the pain as described by the patient was broadly classified into four categories and the results are given in Table II. Pain affecting both lower quadrants or the central region of the abdomen was of ten crampy in nature, whereas pain localized to one or other side was more often aching in type.

TABLE II.-Nature of Abdominal Pain

\begin{tabular}{|c|c|c|c|c|c|c|}
\hline \multicolumn{5}{|c|}{ Nature of Pain } & \multirow{2}{*}{$\begin{array}{c}\begin{array}{c}\text { No. of } \\
\text { Cases }\end{array} \\
161 \\
33 \\
26 \\
161 \\
137 \\
3\end{array}$} & \multirow{2}{*}{$\begin{array}{c}\begin{array}{c}\text { Percentage } \\
\text { Affected }\end{array} \\
30.9 \\
6.3 \\
4.9 \\
30.9 \\
26.3 \\
0.6\end{array}$} \\
\hline $\begin{array}{l}\text { Crampy } \quad . \\
\text { Continuous } \\
\text { Crampy and continuous } \\
\text { Intermittent ache } \\
\text { None } \\
\text { Not known }\end{array}$ & $\begin{array}{l}\because \\
\because \\
\because \\
\therefore\end{array}$ & $\begin{array}{l}\because \\
\because \\
\because \\
\therefore\end{array}$ & $\begin{array}{l}\ddot{2} \\
\ddot{0} \\
\ddot{x}\end{array}$ & $\begin{array}{l}\because \\
\because \\
\because \\
\because\end{array}$ & & \\
\hline Total & .. & .. & .. & .. & 521 & $100 \cdot 0$ \\
\hline
\end{tabular}

Disturbance of Bowel Habit.-Table III shows that disturbances of bowel function, particularly constant constipation or alternating constipation and diarrhoea, occurred more often among women. Bowel disturbance was as common in patients with localized disease as in those with extensive colonic involvement. The incidence of altered bowel habit in cases finally diagnosed as diverticulosis was similar to those finally diagnosed as diverticulitis. The prognosis in patients with normal bowel habit was better than in those with disturbed function. The former were more often symptom-free on leaving hospital and required subsequent hospital readmission less often than patients with altered bowel habit.

TABLE III.-Bowel Habit Before Presentation at Hospital

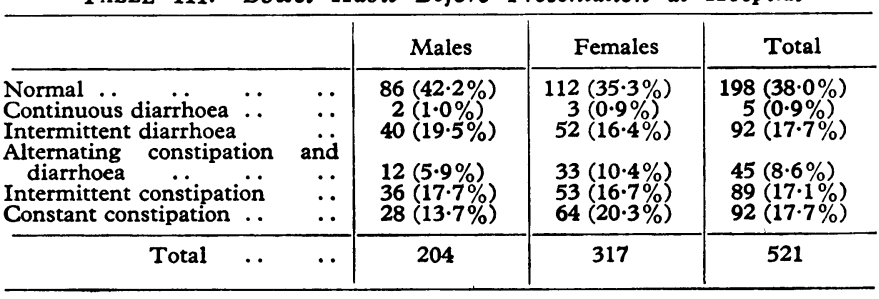

Urinary Symptoms.-Urinary symptoms occurred in $70 \%$ (13\%) of the 521 patients, but it could not be ascertained in $\perp$ every case that diverticular disease was the cause. These symptoms were three times more common where the final diagnosis $N$ was diverticulitis as compared with diverticulosis.

Nausea and Vomiting.-Nausea or vomiting was present in $\vec{\omega}$ $20 \%$ of the patients, and these symptoms were associated with a higher complication rate and a longer stay in hospital, and indicated a worse prognosis.

Flatulence and Heartburn.-More than half of the patients had flatulence and one-third complained of heartburn, but in a proportion of patients these symptoms may have been related to the coexistent upper-intestinal disorders rather than diverticular disease of the colon.

Palpable Mass and Abdominal Distension.-In 20\% of the patients there was a mass in the left lower quadrant palpable either abdominally or per rectum, and about half of them came to surgery. Of the 15 patients who died of diverticular disease during their first hospital admission nine had a palpable swelling in the left iliac fossa. Seventy-four patients (14\%) of the series were noted to be distended on the first admission to hospital, and these had a worse prognosis than the remainder. Patients with a palpable mass in addition to abdominal distension had a worse prognosis than those with either of these signs alone.

Complications.-Spontaneous complications of diverticular disease of the colon which developed before or during the patients' first hospital admission are set out in Table IV.

TABLE IV.-Spontaneous Complications of Diverticular Disease of the

\begin{tabular}{|c|c|c|c|}
\hline Complication & $\begin{array}{c}\text { Males } \\
\text { Males }\end{array}$ & Females & Total \\
\hline 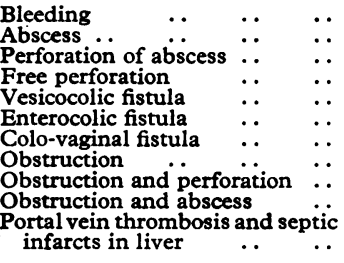 & $\begin{array}{r}46 \\
32 \\
16 \\
5 \\
1 \\
1 \\
0 \\
13 \\
4 \\
3 \\
0\end{array}$ & $\begin{array}{r}73 \\
29 \\
8 \\
9 \\
1 \\
1 \\
1 \\
16 \\
4 \\
1 \\
1\end{array}$ & $\begin{array}{r}119 \\
56 \\
24 \\
14 \\
2 \\
2 \\
1 \\
29 \\
8 \\
4 \\
1\end{array}$ \\
\hline
\end{tabular}

Though frank bleeding occurred in 119 patients it was an indication for surgery on only three occasions. It was noted that patients who bled on one occasion were more likely to bleed again, but the majority who presented with this symptom 8 were not condemned to continuous or recurrent bleeding. Bleeding was not noted in any patient under the age of 40 , but the incidence was similar in each decade after 40 years. $\stackrel{P}{F}$ Surprisingly the frequency of bleeding was slightly higher in the diverticulosis group than in the diverticulitis patients $(29 \%$ 
and $21 \%$ respectively). Pericolic abscesses were twice as common in males as in females, and perforated abscesses were three times as common.

Other Conditions Occurring in Patients with Diverticular Disease of the Colon.-Table V gives the recorded instances of other conditions occurring in the 521 cases of diverticular disease of the colon. It must, however, be emphasized that all patients did not have full investigations, particularly of the upper gastrointestinal tract, and therefore the incidence of lesions was almost certainly higher than recorded here. Cholecystitis with or without gall stones was recorded in $72(14 \%)$ cases, and 61 of these occurred among 317 female patients, an incidence of $19 \%$. Hiatus hernia was noted with about equal frequency in the sexes. Saint's triad (diverticula of colon, hiatus hernia, and cholecystitis) was reported in eight patients $(2 \%)$ and seven of these were women. The tetrad of diverticula of colon, hiatus hernia, cholecystitis, and duodenal ulcer was noted in two cases. Seventeen cases of associated small-bowel diverticulosis were noted in the series-eight involving the duodenum only, five involving jejunum, two involving ileum, one involving both jejunum and ileum, and one involving duodenum and jejunum.

TABLE V.-Pathological Conditions Occurring in 521 Patients with Diverticular Disease of the Colon

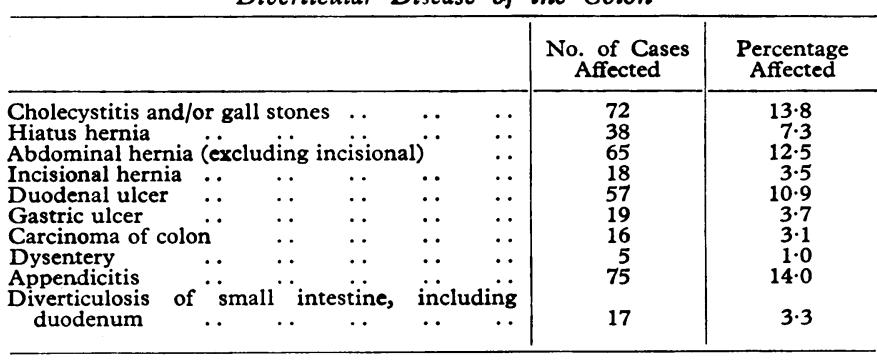

Comparison of Patients with Radiological Diagnosis of Diverticulosis and Diverticulitis.-On first referral to hospital 461 patients had barium enemas performed: 230 were diagnosed radiologically as diverticulosis and 231 as diverticulitis. Some clinical aspects of these two groups are summarized in Table VI. Symptoms were only slightly less common in patients with radiological diverticulosis than in those with changes consistent with diverticulitis. Many of the radiologically diagnosed diverticulosis group had features such as pyrexia, leucocytosis, and various complications, and were considered clinically to have diverticulitis. Of the whole series, all except 95 cases were finally diagnosed on clinical, operative, or necropsy findings as suffering from diverticulitis. Thus the radiological findings alone are deemed insufficient to allow a reliable statement to be made whether or not inflammation is present.

TABLE VI.-Comparison of Various Features in Radiologically Diagnosed Diverticulosis with Radiologically Diagnosed Diverticulitis

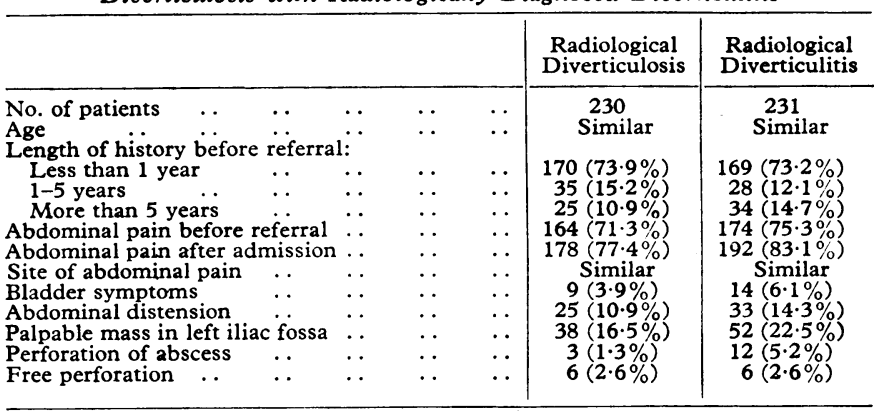

Comparison of Patients with a Final Diagnosis of Diverticulosis and Diverticulitis. - Various aspects of the natural history and clinical features of 95 patients with a final diagnosis of diverticulosis are compared with 426 patients with a final diagnosis of diverticulitis (Table VII). In general, symptoms were less common in patients with a final diagnosis of diverticulosis. Pain, when present, was less severe and tended to be intermittent in character. All the fatalities occurred in cases finally diagnosed as diverticulitis.

TABLE VII.-Comparison of Various Features in Patients Finally Diagnosed as Diverticulosis With Those Finally Diagnosed as Diverticulitis

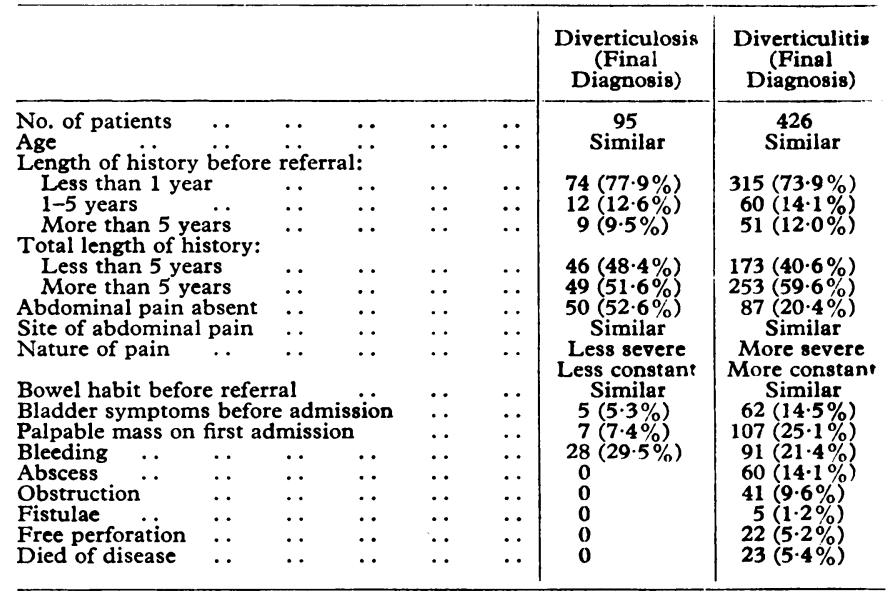

\section{Discussion}

In this review pain in the left lower abdominal quadrant either alone or in combination with other regions was the commonest symptom of diverticular disease of the colon. There was, however, no correlation between the site of pain and the extent of colonic involvement. When pain was more widespread the causal factor was frequently an inflammatory or obstructive complication due to disease in the sigmoid colon. On the other hand, many patients with total or subtotal colonic involvement complained only of pain in the left lower quadrant.

Pain was often present in patients in whom there was little clinical or radiological evidence of inflammation. Morson (1963) has shown that one-third of the specimens resected at St. Mark's Hospital for so-called "diverticulitis" had no macroscopic or microscopical evidence of inflammation. II may be that in this group of patients the pain is often of muscular origin, even to the extent of causing obstructive-type symptoms on occasion.

It was noteworthy that so many patients had radiological changes consistent with inflammatory involvement and yet did not complain of pain as a symptom. It would seem that a low-grade inflammatory process may be present without any notable symptoms. This is also supported by the finding that many patients with a very short history have changes which seem to indicate that an inflammatory process has been in existence for a longer time than the history would suggest.

A high proportion of patients gave a history of disturbed bowel function, but there was little difference in the pattern in patients with extensive disease and in those with localized disease. Patients with normal bowel habit, however, did have a better overall prognosis, in respect of both their immediate outcome of their long-term outlook.

It is sometimes rewarding to do a barium enema on an elderly patient with recurrent urinary symptoms, as diverticular disease of the sigmoid may be the underlying cause even though there are few intestinal symptoms. Although there were only two cases of colovesical fistulae, adherence of inflamed colon to the bladder was much more common, and in some cases urinary symptoms were indicative of an impending fistula.

Apart from inflammation, bleeding was the most common complication of diverticular disease in this survey and corresponds to the commonly reported incidence of 15 to $30 \%$ 
(Morton, 1946 ; Noer, 1955 ; Rushford, 1956 ; Welch and Rodkey, 1956). The age incidence differed from that of Quinn and Ochsner (1953), who reported that most of their patients with this complaint were over the age of 60 , and many had hypertension.

A remarkably high incidence of cholecystitis and/or gall stones in women has been found in this series, and this is all the more significant since every patient did not have a full investigation. The frequency of Saint's triad reported here is less than that of Foster and Knutson (1958), who examined 713 patients by cholecystogram, a radiological series of the upper gastrointestinal tract, and a barium enema and observed an incidence of $3.4 \%$. Boles and Jordan (1958) noted Saint's triad in $6.4 \%$ of their patients with diverticular disease of the colon, and Palmer (1955) reported an incidence of $14 \%$.

Horner (1958) made a specific examination for hiatus hernia in 292 patients with diverticular disease and found an incidence of $16.3 \%$, whereas in 160 control cases he found only a $3 \%$ incidence.

A high incidence of inguinal and femoral herniae has been reported by De La Vega et al. (1964), 20.5\% of 196 cases of diverticular disease of the colon being affected. Again the high incidence in our series raises the question of weakness of the musculature or the connective tissue in these patients.

One of the problems which arises is the difficulty in accurately distinguishing between diverticulosis and diverticulitis. We have shown that it is impossible on radiological grounds to make an accurate distinction between them. Radiology is of primary importance in the initial diagnosis of diverticular disease, but it is often difficult or impossible to determine when inflammaton is present. Some patients may have a minor degree of inflammatory reaction which leads to an erosion and resultant haemorrhage, and yet no clinical or radiological evidence of inflammation is demonstrable. Thus in the present review "diverticulosis" patients had a higher incidence of bleeding than "diverticulitis" patients, but it may be asked whether minor inflammatory reaction was present, at least, in some of the former.
According to Spriggs and Marxer (1927) " any degree of irritation or inflammation may legally be described as diverticulitis, but in practice a distinctive term is needed for the later stage, which constitutes a definite and serious disease from $\underline{\underline{m}}$ which most patients with diverticulosis never suffer." Even if one limits the use of the term to the more obvious clinical 0 involvement, an accurate distinction cannot be made between $ᄃ$ the inflammatory and non-inflammatory group. While the $\overrightarrow{\vec{F}}$ combination of clinical, radiological, and operative findingshelp, in differentiating into two groups, it must be recognized 등 that all have their limitations and the resultant diagnosis may $\frac{\overline{0}}{\overline{0}}$ differ from the pathological findings. Owing to the in- $\vec{\Phi}$ accuracies which surround attempts at distinguishing diverti- $\frac{\Omega}{\Omega}$ culosis from diverticulitis in clinical practice the wider use of $\%$ the term "diverticular disease" is to be preferred.

It is a pleasure to thank Professor H. W. Rodgers, department of surgery, and Professor E. A. Cheeseman, department of statistics, $\vec{\omega}$ Queen's University, Belfast, for providing facilities to undertake this $\frac{O}{\partial}$ investigation. I am indebted to Dr. A. M. Connell for his constant 3 . advice, help, and encouragement throughout the study. I wish to thank the consultant staff of the Royal Victoria Hospital for permission to study patients under their care; Mrs. R. Blackman, who $\infty$ carried out much of the secretarial work connected with the clinical survey ; and Mrs. J. McCabe, who was responsible for the task of $\frac{P}{\mathrm{~N}}$ transferring data to punch cards.

\section{REFERENCES}

Boles, R. S., jun., and Jordan, S. M. (1958). Gastroenterology, 35, 579. De La Vega, J. M., Gonzalez, J. N., and Ponce de Leon, A. (1964). In Gastroenterology, 2 nd ed., edited by H. L. Bockus, p. 919. Philadelphia, Saunders.

Foster, J. J., and Knutson, D. L. (1958). Journal of the American Medi- $\mathbb{\Phi}$ cal Association, 168, 257

Horner, J. L. (1958). American Fournal of Diagnostic Diseases, 3, 343. $\vec{\theta}$

Morson, B. C. (1963). British fournal of Radiology, 36, 385. $3,343.6$

Morton, J. J., jun. (1946). Annals of Surgery, 124, 725 .

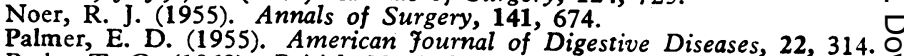

Parks, T. G. (1969). British Medical fournal, 4, 639.

Quinn, $\dot{W}$. C., and Ochsner, A. (1953). American Surgeon, 19, 397

Rushford, A. J. (1956). Proceedings of the Royal Society of Medicine, 49, 577 .

Spriggs, E. I., and Marxer, O. A. (1927). Lancet, 1, 1067

Welch, C. E., and Rudkey, G. V. (1956). Surgery, 39, 712

\title{
Critical Study of 5\% Guanethidine in Ocular Manifestations of Graves's Disease
}

\author{
N. E. F. CARTLIDGE,* M.B., M.R.C.P. ; A. L. CROMBIE, $†$ M.B., F.R.C.S.ED. ; J. ANDERSON, $\ddagger$ M.B., M.R.C.P. \\ R. HALL, $\S$ M.D., B.SC., M.R.C.P.
}

\begin{abstract}
Summary : Assessment was made of $5 \%$ local guanethidine in treating eye manifestations in euthyroid patients with either treated thyrotoxicosis or ophthalmic Graves's disease. In a double-blind crossover study guanethidine caused greater improvement in lid retraction than a control solution. A long-term study showed that this improvement was maintained. A much lower incidence of side-effects was noted with $5 \%$ guanethidine than with $10 \%$ solution.
\end{abstract}

\section{Introduction}

Previous studies (Sneddon and Turner, 1966 ; Crombie and Lawson, 1967 ; Bowden and Rose, 1969 ; Cant, Lewis, and
Harrison, 1969) have shown that certain of the ocular manifestations of Graves's disease respond to local application of adrenergic blocking agents. Of these a $10 \%$ solution of guanethidine has been shown to give the best results, though in this concentration treatment is accompanied by a relatively high incidence of local side-effects, notably punctate keratitis (Crombie and Lawson, 1967). It has been suggested that a $5 \%$ solution will cause a lower incidence of side-effects with only slight reduction in efficacy. The purpose of this paper is to report a double-blind controlled study of $5 \%$ local guane-

- Senior House Officer, Department of Medicine.

t Consultant Ophthalmologist.

¥ First Assistant, Department of Medicine.

Censultant Physician.

Royal Victoria Infirmary, Newcastle upon Tyne NE1 4LP. 